\title{
Ionic equilibria in aqueous organic solvent mixtures. Speciation of hydrofluoric acid in several ethanol/water solutions.
}

\author{
Clara Ràfols, José Luis Beltrán*, Martí Rosés, Elisabeth Bosch \\ Departament d'Enginyeria Química i Química Analítica, \\ Universitat de Barcelona, \\ Martí i Franquès 1-11, 08028-Barcelona, Spain
}

* Corresponding author: J.L. Beltrán (jlbeltran@ub.edu)

\begin{abstract}
The presence of different species derived from hydrofluoric acid, together with the corresponding formation equilibria, has been investigated in $70 \%(\mathrm{w} / \mathrm{w})$ ethanol/water solutions at analytical concentrations up to $5 \mathrm{~mol} \mathrm{~L}^{-1}$. In the same way, hydrofluoric acid solutions in $50 \%(\mathrm{w} / \mathrm{w})$ (up to $2 \mathrm{~mol} \mathrm{~L}^{-1}$ ) and in $30 \%(\mathrm{w} / \mathrm{w})$ ethanol/water (at 0.003-0.005 mol L-1) have been examined too. Conductometric and potentiometric (glass electrode and fluoride-ion-selective electrode) measurements have been used to demonstrate that $\mathrm{HF}$ and $\mathrm{HF}_{2}$ predominate in dilute solutions regardless the solvent composition, whereas HF and polyhomoconjugated species prevail in the concentrated ones.

Thermodynamic dissociation and homoconjugation constants have been determined in hydrofluoric acid dilute solutions. The more ethanol is contained in the solvent, the higher is the formation constant for the homoconjugated species (between 1.1 and 1.3 as $\log \mathrm{K}_{\text {homo }}$ ). In concentrated HF solutions at $70 \%$ and $50 \%(\mathrm{w} / \mathrm{w})$ ethanol/water medium, the polyhomoconjugated species $\mathrm{H}_{2} \mathrm{~F}_{3}$ (in $70 \%$ and $50 \%$ ethanol/water) and $\mathrm{H}_{3} \mathrm{~F}_{4}^{-}$(in 70\% ethanol/water) are formed, with successive formation constants between about 4.1 and 6.9 logarithmic units, being the values obtained for the first homoconjugated species (about 1.2 in logarithmic units), very close to those obtained in dilute HF solutions.
\end{abstract}

Keywords: Hydrofluoric acid; Ethanol-water mixtures; Combination-Glass electrode; Fluoride-ion-selective electrode; Speciation; Equilibrium constants. 


\section{Introduction}

The technological significance of hydrofluoric acid solutions on the etching of silica surfaces [1-5], on the pores size diameter of silicon membranes [6] or on the pore diameter of electrochemically formed porous silicon [7] has been widely reported. Nevertheless, the specific chemical reactions involved in the mentioned matters are not completely understood, despite the role of conjugated species of hydrofluoric acid seems to be very significant.

In fact, most speciation studies have been performed in aqueous solutions, being the main subjects the effect of the overall hydrofluoric acid concentration on the formation of conjugated species, and the ion-pair formation between the anionic conjugated species and $\mathrm{H}_{3} \mathrm{O}^{+}$in very concentrated solutions [8]. In his detailed study, Kolasinski [9] concludes that, for solutions up to $2 \mathrm{~mol} \mathrm{~kg}^{-1}$, an accurate description of solution composition can be obtained considering only the acidic dissociation and also the formation of the simplest homoconjugate species, $\mathrm{HF}_{2}$. Above this concentration, ion-ion interactions and/or other equilibria make calculations less reliable but still useful up to $6 \mathrm{~mol} \mathrm{~kg}^{-1}$. It is also advised about additional complications due to the non-ideality of fluoride solutions. Coupling both items, multiple equilibria and non-ideality, cumbersome numerical calculation were required to achieve accurate activity estimates for the species present in $0.1-6.0$ mol kg-1 concentration range [9]. In addition, since one of the common uses of hydrofluoric acid solutions is the silica attack, the silica solubility and dissolution rate by means of acidic fluoride solutions was studied by Mitra et al. [10] concluding that dissolution rates for quartz and also for amorphous silica were related to the activities of the species present in the solution.

Nevertheless, most practical usages use hydrofluoric acid solutions prepared in hydroalcoholic solvents, mainly ethanol/water mixtures, and it is well known that the presence of ethanol as water-cosolvent changes dramatically the occurrence of the solute species and their formation constants. A first report about this item was published by Luxemberg et al. [11] reporting equilibrium data for $\mathrm{HF}$ and $\mathrm{HF}_{2}{ }^{-}$ formation in ethanol/water solutions up to $70 \%(\mathrm{w} / \mathrm{w})$, which were after fitted vs. the solvent composition by means of quadratic polynomials [4]. However, the most interesting solutions are those with $86.2 \%(\mathrm{w} / \mathrm{w})$ of ethanol because of its wide technological application. In this medium composition only $\mathrm{F}^{-}$and $\mathrm{HF}$ are the 
species present in very diluted solutions $\left(\mathrm{C}_{\mathrm{HF}}<10^{-3} \mathrm{~mol} \mathrm{~L}^{-1}\right)$, whereas in moderately diluted ones $\left(\mathrm{C}_{\mathrm{HF}}\right.$ in the $10^{-2}-10^{-1} \mathrm{~mol} \mathrm{~L}^{-1}$ range) $\mathrm{F}^{-}, \mathrm{HF}$ and $\mathrm{HF}_{2}^{-}$are significantly present, being the homoconjugated species the predominant ones. However, for concentrated $\mathrm{HF}$ solutions $\left(\mathrm{C}_{\mathrm{HF}}>1 \mathrm{~mol} \mathrm{~L}^{-1}\right)$ polyhomoconjugation becomes very significant. Specifically, for the widely used $\mathrm{C}_{\mathrm{HF}}=2.2 \mathrm{~mol} \mathrm{~L}^{-1}$, resulting of a ten times dilution of the commercial $40 \%$ aqueous hydrofluoric acid in pure ethanol, highly polyhomoconjugated species, including those with 7 or 8 monomers, are detected. In fact, up to $26 \%$ of hydrofluoric acid is in polyhomoconjugated form in this very used etching solution [11, 12]. In any case, the final goal of these studies was to relate the predominant species in the commonly used hydrofluoric acid solutions to their technological role. As far as we known, the significance of highly homoconjugated species in the etching of silica surfaces and in the control of silicon porosity seems to be widely demonstrated.

In this work, an accurate study about the speciation of hydrofluoric acid in ethanolwater solutions containing $70 \%, 50 \%$ and $30 \%(\mathrm{w} / \mathrm{w})$ has been carried out, in a wide range of solute concentration. In particular, in 50\% ethanol/water medium the speciation has been studied up to $2.2 \mathrm{~mol} \mathrm{~L}^{-1}$. On the other hand, the maximum $\mathrm{HF}$ concentration in $70 \%$ ethanol/water solutions was about $5.0 \mathrm{~mol} \mathrm{~L}^{-1}$, as we expected that these conditions should favor the formation of the higher homoconjugated species. The results should allow a more accurate selection of the appropriate solutions for each practical application.

\section{Experimental}

\subsection{Apparatus}

For conductometric measurements a Radiometer CDM 83 conductometer and a Radiometer CDC 304 cell were used.

For potentiometric measurements, a $10 \mathrm{~mL}$ Metrohm 665 Dosimat microburette, equipped with exchange units of 5 and $50 \mathrm{~mL}$, and a Crison Digilab 2002 micropH-meter provided with the suitable electrode systems were employed. Hydrogen ion measurements were made by a Crison 52-06 combined glass electrode ( $\mathrm{HF}$ resistant up to $1 \mathrm{~g} \mathrm{~L}^{-1}$, and recommended for $1-11 \mathrm{pH}$ range). Fluoride ion measurements were performed with a $\mathrm{LaF}_{3}$ fluoride-ion-selective 
electrode (Ingold 120/S7) and a Ag|AgCl|KCl $3 \mathrm{~mol} \mathrm{~L}^{-1}$ reference electrode (Crison $52-41)$.

\subsection{Chemicals}

Chemicals used were hydrofluoric acid (Merck, G.R. 40\%), hydrochloric acid (Merck, G.R. 25\%), potassium hydroxide $0.5 \mathrm{~mol} \mathrm{~L}^{-1}$ in ethanol (Carlo-Erba), benzoic acid (Carlo Erba, RS-STD), and potassium fluoride (Aldrich 99\%) dried at $100 \pm 0.5{ }^{\circ} \mathrm{C}$ during two hours before use. Solvent mixtures were prepared from anhydrous ethanol (Merck gradient grade for chromatography) and triply distilled water.

\subsection{Experimental Procedures}

\subsubsection{Conductometric measurements}

The cell constant $\left(1.000 \pm 0.011 \mathrm{~cm}^{-1}\right)$ was determined from the conductance of a $0.0100 \mathrm{~mol} \mathrm{~kg}^{-1} \mathrm{KCl}$ solution measured at $25.0 \pm 0.2^{0} \mathrm{C}$. To determine $\mathrm{KF}$ dissociation constant, 15 solutions of electrolyte in the working solvents (ethanol/water $70 \%$ and $50 \%(\mathrm{w} / \mathrm{w})$ of ethanol) were prepared by successive additions of a KF solution of known concentration $\left(2 \times 10^{-2} \mathrm{~mol} \mathrm{~L}^{-1}\right)$ to the working solvents and their conductances were measured. All measurements were made in the $4 \times 10^{-5}$ to $6 \times 10^{-3} \mathrm{~mol} \mathrm{~L}^{-1}$ concentration range.

\subsubsection{Glass electrode potentiometric measurements.}

Standardization of the combined glass electrode was done by successive additions of $0.1 \mathrm{~mL}$ until a total of $2.5 \mathrm{~mL}$ of $1 \mathrm{~mol} \mathrm{~L}^{-1} \mathrm{HCl}$ (prepared with the working solvent) to $25 \mathrm{~mL}$ of working solvent -ethanol/water $70 \%, 50 \%$ or $30 \%$ $(\mathrm{w} / \mathrm{w})$ of ethanol- in an externally thermostated vessel $\left(25.0 \pm 0.1^{\circ} \mathrm{C}\right)$. The stability criterion to take reliable potential measurements was to admit variations equal or lesser than $0.2 \mathrm{mV}$ in $2 \mathrm{~min}$. The potential was related to the hydrogen ion activity $\left(a_{H^{+}}\right)$from the hydrogen ion concentration and the extended Debye-Hückel expression:

$\log \gamma_{H^{+}}=-\frac{A \sqrt{I}}{1+a_{0} B \sqrt{I}}$ 
where $\gamma_{\mathrm{H}_{+}}$indicates the activity coefficient of the hydrogen ion and $/$the ionic strength of the medium in molal scale. The coefficients $\left(A=1.5130, a_{0} B=2.1559\right.$; $A=1.0333, a_{0} B=1.8986$ and $A=0.7421, a_{0} B=1.7002$ for ethanol/water $70 \%, 50 \%$ and $30 \%(w / w)$ of ethanol, respectively, all of them at $\left.25.0 \pm 0.1{ }^{0} \mathrm{C}\right)$ were obtained from the literature $[13,14]$.

The equilibrium constants involved in hydrofluoric acid system were determined from the potentials measured along titrations of 25 or $50 \mathrm{~mL}$ of hydrofluoric acid solutions of about $3-5 \times 10^{-3} \mathrm{~mol} \mathrm{~L}^{-1}$ with $\mathrm{KOH}$. Titrant solutions were obtained from dilution with water of the $\mathrm{KOH} 0.5 \mathrm{~mol} \mathrm{~L}^{-1}$ stock solution prepared in pure ethanol to obtain the suitable ethanol contents $(70 \%, 50 \%$ or $30 \%(w / w)$ of ethanol) and properly standardized against benzoic acid. VALORA program was used for titration control [15].

\subsubsection{Fluoride-ion-selective electrode potentiometric measurements.}

The fluoride-ion-selective/reference electrode system was standardized with known concentration KF solutions, about $7 \times 10^{-4} \mathrm{~mol} \mathrm{~L}^{-1}$, prepared from the dried salt and the working solvent (ethanol/water $70 \%$ or $50 \%(\mathrm{w} / \mathrm{w})$ of ethanol). The potential of solutions resulting from successive additions of KF solutions to the binary solvent were measured. The potential stability criterion was again to keep a variation lesser than $0.2 \mathrm{mV}$ in $2 \mathrm{~min}$.

To measure the fluoride activity in concentrated solutions, $25 \mathrm{~mL}$ of 2 or $5 \mathrm{~mol} \mathrm{~L}^{-1}$ hydrofluoric acid solutions (prepared by mixing the commercial product with ethanol until the working ethanol contents) were diluted by means of successive additions (from 1 to $55 \mathrm{~mL}$ ) of the working solvent and their potential measured. The potential stability criterion was to admit a variation lesser than $0.3 \mathrm{mV}$ in 3 min. The exact HF concentration was determined by titration with $\mathrm{KOH}$.

All measurements were done at $25.0 \pm 0.1^{\circ} \mathrm{C}$ in a water-jacket thermostated vessel. Polyethylene vessels were used when HF was present in the working solution. 


\subsection{Data treatment}

Conductometric measurements were analyzed by means of the Debye-HückelOnsager and Shedlovsky equations [16, 17] using the non-linear least squares fitting program KCONDUCT [12]. In this way, Debye-Hückel-Onsager equation can be resolved by Fuoss-Kraus method which use the following equation, in which $\Lambda_{o}$ and $K$ can be computed from the plot of $F(z) / \Lambda$ vs. $c \wedge y^{2} / F(z)$ :

$\frac{F(z)}{\Lambda}=\frac{1}{\Lambda_{0}}+\frac{c \Lambda \gamma_{ \pm}^{2}}{\Lambda_{0}^{2} K F(z)}$

being $K$ the dissociation constant of $\mathrm{KF}, \Lambda$ and $\Lambda_{0}$ the equivalent and limiting equivalent conductivities, respectively, $V_{ \pm}$the mean activity coefficient (calculated after the Debye-Hückel equation) and $F(z)$ is the continuous fraction:

$F(z)=1-z\left(1-z\left(1-z(1-\cdots)^{-1 / 2}\right)^{-1 / 2}\right)^{-1 / 2}$

in which $z$ is the expression:

$z=S \Lambda_{0}^{-3 / 2}(c \Lambda)^{1 / 2}$

and

$S=8.18 \cdot 10^{5} \frac{\Lambda_{0}}{(\varepsilon T)^{3 / 2}}+\frac{82}{\eta(\varepsilon T)^{1 / 2}}$

A similar procedure is used for the Shedlovsky method, but using the equations:

$\frac{1}{\Lambda S(z)}=\frac{1}{\Lambda_{0}}+\frac{c \Lambda S(z) \gamma_{ \pm}^{2}}{K \Lambda_{0}^{2}}$

$S(z)=\left\{z / 2+\left[1+(z / 2)^{2}\right]^{1 / 2}\right\}^{2}$

On the other hand, the equilibrium constants of hydrofluoric acid system were determined from potentiometric measurements by means of a modified version of the PKPOT software [18], in order to accommodate the experimental data. The main core of this software is the mass-balance solution procedure, described previously [19], but adapted in this case to deal with solutions of variable ionic strength. In fact, PKPOT uses two sets of overall formation constants, corresponding to thermodynamic and concentration constants $\left(\beta^{0}\right.$ and $\beta^{c}$, respectively); for a certain $k$ species in equilibrium, both constants are related according to: 


$$
\log \beta_{k}^{c}=\log \beta_{k}^{0}-\delta \beta_{k} \cdot \log \gamma_{ \pm}
$$

where $\delta \beta_{k}$ is a term related with the charge of the $k$ species.

For each experimental point, the values of the different $\beta_{k}^{c}$ values are set equal to the corresponding $\beta_{k}^{0}$, and the mass-balance is solved iteratively; in each iteration, the program calculates the concentration of all species described in the model in $\mathrm{mol} \cdot \mathrm{L}^{-1}$. These concentrations are changed to $\mathrm{mol} \cdot \mathrm{kg}^{-1}$ units (molal scale), taking into account the density of the medium, in order to calculate the ionic strength of the solution (in mol.kg-1 units) used in the Debye-Hückel equation to determine the activity coefficients, and new values for the constants are calculated after equation (8). This procedure is repeated until the mass balances are solved. The theoretical e.m.f. for this point is determined from the calculated free concentration of the measured component ( $\mathrm{H}+$ or $\left.\mathrm{F}_{-}\right)$and the conditional standard potential of the electrode and their slope. In this way, although there is a set of thermodynamic equilibrium constants, they change to concentration constants in each experimental data point.

On the other hand, the set of equilibrium constants is refined following an iterative Gauss-Newton algorithm [20]; in this case, an objective function $(U)$ is defined as the weighed sum of squared differences between experimental and calculated cell potentials:

$U=\sum_{i=1}^{n t} \sum_{j=1}^{n p, i} w_{i, j}\left(E_{i, j, \text { exp }}-E_{i, j, c a l c}\right)^{2}$

where $n t$ indicates the number of titrations analyzed, and $n p, i$ the number of data points in the $i$-titration. $E_{i, j, e x p}$ is the measured potential of the j-point of the $\mathrm{i}$ titration, and $E_{i, j, \text { calc }}$ the corresponding calculated according to the equilibrium model. The term $w_{i, j}$ is the weighing factor corresponding to the $i$-point in the $j$ titration, and it is calculated from the estimated errors in the titrant volume and measured potential ( $\sigma_{V}$ and $\sigma_{E}$, respectively) and the slope of the titration curve at each point:

$w_{i, j}=\frac{1}{\sigma_{E}^{2}+(\partial E / \partial V)_{i, j}^{2} \sigma_{V}^{2}}$

The derivatives $\partial \mathrm{E} / \partial \mathrm{V}$ are calculated by a $3^{\text {rd }}$ degree polynomial approximation, fitted to a five-point moving window through the titration curve. The $\sigma_{E}$ value was 
set to $0.2 \mathrm{mV}$, and $\sigma_{\mathrm{V}}$ was set to 0.002 and $0.01 \mathrm{~mL}$ for $5 \mathrm{~mL}$ and $50 \mathrm{~mL}$ burette cylinders, respectively.

In this way, the data points corresponding to buffered zones have more statistical weight in the calculations than those obtained near the equivalence point of the titrations, which present poorer precision.

The iterative process is repeated until a minimum in the $U$ function is attained. This procedure has been used in the potentiometric determination of equilibrium constants using $\mathrm{H}^{+}$and $\mathrm{F}^{-}$ion-selective electrodes.

The fit of model to experimental data is measured as the standard deviation of residuals $(s d)$ :

$s d=\sqrt{\frac{U}{n-n_{\text {ref }}}}$

being $n$ the number of the data points analyzed, and $n_{\text {ref }}$ the number of parameters adjusted simultaneously.

\section{Results and discussion}

\subsection{Conductometric measurements of potassium fluoride dissociation}

The KF dissociation constants in the selected binary solvents were determined according to the Shedlovsky approach [16]. The physical constants of the used ethanol-water mixtures, as well as the obtained dissociation constants, $\mathrm{pK}^{0}$ salt, and limiting conductivities, $\Lambda_{0 \text {,salt, }}$ are shown in Table 1. No data for the water richest solution are included because of the very wide salt dissociation. According to the Born model [21], the $\mathrm{pK}_{\text {salt }}$ decreases with the reverse of the solvent permittivity. However, the $\Lambda_{0 \text { salt }}$ value shows a minimum around the $70 \%(w / w)$ of ethanol, which, according to the Walden's rule, can be related to the maximum of viscosity at mole fraction about $0.3(50 \%(\mathrm{w} / \mathrm{w}))$ shown by the ethanol-water mixtures [22, 23, 26].

3.2 Hydrogen ion potentiometric measurements of dilute hydrofluoric acid (about $\left.2 \times 10^{-3} \mathrm{~mol} \mathrm{~L}^{-1}\right)$ in $70 \%, 50 \%$ and $30 \%(\mathrm{w} / \mathrm{w})$ ethanol/water solvents 
The calibration of the electrode system showed a nerstian response, but a significant acidic junction potential $\left(\mathrm{E}_{\mathrm{j}}=\mathrm{j}_{\mathrm{a}} \mathrm{a}_{\mathrm{H}^{+}}\right)$at $\mathrm{pH}$ values below 2.5 for solutions with $70 \%$ or $50 \%$ and below 1.7 for $30 \%$ of ethanol content was observed [27]. So, the measured potential is related with the hydrogen ion activity according to the following equation:

$$
E=E^{0}+j_{a} a_{H^{+}}-59.16 p H
$$

The obtained $E^{0}$ and $j_{a}$ values for the different working solvents were $375 \pm 1$ and $252 \pm 30,385 \pm 2$ and $102 \pm 24$, and $405 \pm 1$ and $27 \pm 5 \mathrm{mV}$ for $70 \%, 50 \%$, and $30 \%$ $(\mathrm{w} / \mathrm{w})$ ethanol/water solvents, respectively.

PKPOT software [18] was used for the calculation of the thermodynamic equilibrium constants (indicated as $\beta_{\mathrm{H}, \mathrm{F}}^{0}$ ) of the different $\mathrm{HF}$ species at dilute concentrations, taking into account the dissociation of $\mathrm{KF}\left(\mathrm{K}^{0}\right.$ salt $)$ given in Table 1 , obtained by conductometry. Thus, the following equilibria were taken in consideration:

$$
\begin{array}{ll}
\mathrm{H}^{+}+\mathrm{F}^{-} \mathrm{HF} & \beta_{1,1}^{0}=\frac{[H F]}{\left[F^{-}\right]\left[H^{+}\right] \gamma_{ \pm}^{2}} \\
\mathrm{H}^{+}+2 \mathrm{~F}^{-} \leftrightarrows \mathrm{HF}_{2}^{-} & \beta_{1,2}^{0}=\frac{\left[H F_{2}^{-}\right]}{\left[H^{+}\right]\left[F^{-}\right]^{2} \gamma_{ \pm}^{2}} \\
\mathrm{~K}^{+}+\mathrm{F}^{-} \leftrightarrows \mathrm{KF} & \beta_{\text {salt }}^{0}=\frac{[K F]}{\left[F^{-}\right]\left[K^{+}\right] \gamma_{ \pm}^{2}}=\frac{1}{K_{\text {salt }}^{0}}
\end{array}
$$

From the equations 13 and 14, the dissociation and homoconjugation constants $\left(\mathrm{K}_{\text {homo }}\right)$, can be derived as

$$
\begin{array}{ll}
\mathrm{HF} \leftrightarrows \mathrm{H}^{+}+\mathrm{F}^{-} & K_{a}^{0}=\frac{1}{\beta_{1,1}^{0}} \\
\mathrm{HF}+\mathrm{F}^{-} \leftrightarrows \mathrm{HF}_{2}^{-} & K_{\text {homo }}^{0}=\frac{\beta_{1,2}^{0}}{\beta_{1,1}^{0}}
\end{array}
$$

Since the salt dissociation is much higher than the one of HF species, the formation of KF ion-pairs has only a small effect close to the titration equivalence point, where salt concentration is relatively high [17].

The results obtained are gathered in Table 2 (as $\mathrm{pK}_{\mathrm{a}}^{0}$ and $\log \mathrm{K}_{\text {homo) }}^{0}$ ), together with the available data from literature. A good agreement is shown between the obtained values with those previously published, with some differences (about 0.1 units) in $\mathrm{pK}_{\mathrm{a}}$ and log $\mathrm{K}_{\text {homo }}$ values at $70 \%(\mathrm{w} / \mathrm{w})$ ethanol/water medium. These 
differences can be attributed to the fact that Luxemberg's values [11] were calculated assuming overall dissociation of $\mathrm{KF}$, whereas we use $\mathrm{pK}^{0}$ salt values presented in Table 1.

Figure 1 presents a set of $\mathrm{pH}$ titrations, corresponding to $30 \%$ ethanol/water solutions. It is shown that near the equivalence points the curves are steep, indicating the need of the weighing factors in the data treatment.

The complete series of $\mathrm{pK}_{\mathrm{a}}$ values shown in Table 2 (solvents from 0 to $91.3 \%$ of ethanol) has been correlated with the ethanol contents in the hydroalcoholic mixtures, eq. (18), being $c$ the percentage of ethanol in the solvent mixture:

$\mathrm{pK}_{\mathrm{a}}^{0}=3.42( \pm 0.09)+4.15( \pm 0.23) \times 10^{-4} \mathrm{c}^{2}$

d.f. $=7 ;$ s.d. $=0.15 ; r=0.991$

Similarly, the whole set of log $\mathrm{K}^{\circ}$ homo values shown in Table 2 is correlated with the solvent composition. Despite the evidence of partial salt dissociation effect, no correction of published results can be embodied in this instance since only the final mean value is available. Therefore, associated statistical parameters are poorer than those achieved for eq. (18). Thus,

$\log \mathrm{K}_{\text {homo }}^{0}=0.74( \pm 0.10)+1.47( \pm 0.26) \times 10^{-4} \mathrm{c}^{2}$

d.f. $=7 ;$ s.d. $=0.16 ; r=0.920$

Final results fittings are shown in Fig. 2.

3.3 Fluoride potentiometric measurements in hydrofluoric acid in $70 \%(\mathrm{w} / \mathrm{w})$ and in $50 \%(w / w)$ ethanol/water solvents.

A previous study [12] performed in a solution of $91.3 \%(\mathrm{w} / \mathrm{w})$ of ethanol and relatively concentrated hydrofluoric acid solutions (up to $2.2 \mathrm{~mol} \mathrm{~L}^{-1}$ ) pointed out the presence of polyhomoconjugated species with high aggregation degree (from 6 to 9 monomers). It is well known that the formation of conjugated species is strongly conditioned by the medium permittivity and the overall hydrofluoric acid concentration, $\mathrm{C}_{\mathrm{HF}}$. To verify the effect of these parameters on the system under study, potentiometric measurements in higher permittivity media $(70 \%$ and $50 \%$ $(\mathrm{w} / \mathrm{w})$ of ethanol) and similar concentration (up to $2.3 \mathrm{~mol} \mathrm{~L}^{-1}$ ) have been 
performed. Nevertheless, the commercial glass electrode is able to work properly until about $1 \mathrm{~g} \mathrm{~L}^{-1}\left(0.05 \mathrm{~mol} \mathrm{~L}^{-1}\right)$ of hydrofluoric acid but it can be seriously damaged in more concentrated solutions. Therefore, a fluoride-ion-selective electrode was chosen to investigate the solutions of interest. In both instances, the electrode standardization showed a quasi-nernstian behavior and a linear range potential (E) vs pF (-log $\left.a_{F^{-}}\right)$wide enough, but about two pF units shorter than the one estimated by the manufacturer for aqueous solutions (see Table 3). All subsequent measurements were done in the linearity range.

On the other hand, a higher dispersion has been observed in the conditional standard potential of the fluoride ion-selective electrode (compared with the glass electrode); this dispersion increasing moderately with the ethanol content of the medium.

Since in very high ethanol content medium, neutral dimers or polymers of hydrofluoric acid were not found at all [12], their absence in the present working solutions is assumed. Then, only the presence of mono and polyhomoconjugated species is postulated, and the pertinent formation equations formulated from the simplest ionic species as required by PKPOT software. Thus, the different models tested contained the formation equilibria of the species $\mathrm{HF}$ and $\mathrm{HF}_{2}^{-}$(see equations 13 and 14), together with the polyhomoconjugated species:

$$
\mathrm{nH}^{+}+(\mathrm{n}+1) \mathrm{F}^{-} \leftrightarrows \mathrm{H}_{\mathrm{n}} \mathrm{F}_{\mathrm{n}+1}^{-} \quad \quad \boldsymbol{\beta}_{n, n+1}^{0}=\frac{\left[H_{n} F_{n+1}^{-}\right]}{\left[H^{+}\right]^{n}\left[F^{-}\right]^{n+1} \gamma_{ \pm}^{2 n}}
$$

The potentiometric data were treated with the PKPOT program [18], testing different models starting with the simplest species ( $\mathrm{HF}$ and $\mathrm{HF}_{2}{ }^{-}$). Taking into account this basic model, the successive addition of species with the general formula $\mathrm{H}_{\mathrm{n}} \mathrm{F}_{\mathrm{n}+1}{ }^{-}$was tested. In each case, the simultaneous refinement of all the equilibrium constants involved -applied to all titration data in each working solventwas carried out. A new species was accepted when a significant reduction in the $U$ function -eq. (9)- was obtained, and the estimated relative error in the value of the formation constant was lower than $20 \%$, which represents an estimated error in log $\mathrm{K}$ lower than \pm 0.09 units. The model was considered completed when no further significant improvement in the $U$ function was obtained.

It must be noted that the results obtained represents to data sets corresponding to solute concentrations between $0.6-2.0 \mathrm{~mol} \mathrm{~L}^{-1}$ and $0.6-5.0 \mathrm{~mol} \mathrm{~L}^{-1}$, at $50 \%$ and 
$70 \%(\mathrm{w} / \mathrm{w})$ of ethanol, respectively. In these conditions, the activity coefficients calculated by the Debye-Hückel equation (as used in PKPOT) are no longer valid because of the calculated ionic strength (up to about 0.2-0.3 mol L-1). On the other hand, we have assumed that the activity coefficient for uncharged species (as HF) is equal to the unity; this fact could be also a source of error, as most hydrofluoric acid exists as the HF species. At these concentrations, interactions between HF molecules surely will exist, and therefore their activity coefficient will not equal to unity. Unfortunately, there is no literature data about thermodynamic parameters of speciation of $\mathrm{HF}$ at these concentration levels $\left(2\right.$ to $\left.5 \mathrm{~mol} \mathrm{~L}^{-1}\right)$ in ethanol/water mixtures, and therefore is not possible to work with "true" thermodynamic equilibrium constants.

However, we have used the activity coefficients by the Debye-Hückel in order to obtain a set of "working equilibrium constants" $\left(\beta^{\mathrm{w}}\right)$ suitable to determine the hydrofluoric acid speciation at concentration levels up to $2-5 \mathrm{~mol} \mathrm{~L}^{-1}$ (for $50 \%$ and $70 \%$ of ethanol, respectively). In this way, concentration equilibrium constants can be calculated by PKPOT at each titration data point.

Table 4 shows the set of optimized equilibrium constants obtained by PKPOT for the $50 \%$ and $70 \%$ ethanol/water $(\mathrm{w} / \mathrm{w})$ medium. In the first medium, the model contains the species $\mathrm{HF}, \mathrm{HF}_{2}$ and $\mathrm{H}_{2} \mathrm{~F}_{3}$. The model obtained for $70 \%$ ethanol/water (w/w) medium contains these species, with the addition of the $\mathrm{H}_{3} \mathrm{~F}_{4}$ species. From these constants, we have calculated the successive "working" homoconjugation constants $\left(\mathrm{K}^{\mathrm{w}}\right.$ homo $)$, which are given in Table 5 .

As a working example, Fig 3 shows the experimental and calculated titration data obtained for 12 potentiometric titrations corresponding to the $70 \%(\mathrm{w} / \mathrm{w})$ ethanol/water medium ( $\mathrm{C}_{\mathrm{HF}}$ values indicated in the figure), which were treated simultaneously with PKPOT. Figure 3 indicates also that the slope of the curves is very smooth in all cases, thus in this case the statistical weights of each data point are taken to the unity (they were calculated, but the differences were not significant). The agreement between experimental and calculated titration curves indicates the good fit of the equilibrium model to experimental data. 
3.4 Speciation in the whole concentration range examined in $70 \%(w / w)$ ethanol/water solvent

The concentration of the hydrofluoric acid species vs. its overall concentration has been calculated from the constants given in Table 4, and is presented in Figure 4. It shows that HF is the predominant species in the whole concentration range, whereas the $\mathrm{F}^{-}$concentration shows relatively small changes in the range calculated. The progressive formation of polyhomoconjugated species increases with the total concentration of HF.

\section{Conclusions}

It has been demonstrated the suitability of glass electrode to work in dilute solutions of hydrofluoric acid (about $3-5 \times 10^{-3} \mathrm{~mol} \mathrm{~L}^{-1}$ ) prepared in ethanol-water mixtures of $70 \% 50 \%$ and $30 \%(\mathrm{w} / \mathrm{w})$ in ethanol. The experimental measurements show that the main species present in these solutions are $\mathrm{H}^{+}, \mathrm{F}^{-}, \mathrm{HF}$ and $\mathrm{HF}_{2}$. More concentrated solutions prepared with solvent mixtures of $50 \%$ and $70 \%$ $\left(\mathrm{w} / \mathrm{w}\right.$ ) in ethanol (up to about $2.2 \mathrm{~mol} \mathrm{~L}^{-1}$ and $5 \mathrm{~mol} \mathrm{~L}^{-1}$, respectively) have been successfully investigated by means of a fluoride-ion-selective electrode. The speciation in these conditions indicates that the free fluoride concentration remains relatively constant (between $2 \times 10^{-4}$ and $2 \times 10^{-3}$ depending on ethanol content) in the range of total hydrofluoric concentrations investigated, being the HF the predominant species in solution.

In addition, it should be noted the agreement between the dissociation constant of $\mathrm{HF}$ in $70 \%$ and $50 \%$ water/ethanol obtained by two different procedures: by titration using a pH electrode at dilute $\mathrm{HF}$ concentration $\left(3-5 \times 10^{-3} \mathrm{~mol} \mathrm{~L}^{-1}\right)$ and titration using a pF electrode at higher $\mathrm{HF}$ concentrations $\left(2\right.$ and $\left.5 \mathrm{~mol} \mathrm{~L}^{-1}\right)$. The values obtained by $\mathrm{pH}$ titration are 5.40 and 4.50 (Table 2, as $\mathrm{pK}^{0} \mathrm{a}$, at $70 \%$ and $50 \%$ ethanol/water, respectively), whereas the obtained by $\mathrm{pF}$ titration are 5.60 and 4.57 (Table 4 , as $\log \beta^{\mathrm{w}}{ }_{\mathrm{HF}}$, at $70 \%$ and $50 \%$ ethanol/water, respectively). These small differences, as well as the ones for the first homoconjugation constant, between the results obtained by means of $\mathrm{pH}(1.30$ and 1.14 , at $70 \%$ and $50 \%$ ethanol content, Table 2 ) and pF electrodes (1.22 and 1.19 , at $70 \%$ and $50 \%$ ethanol content, respectively, as show on Table 5) can be attributed to the different concentration ranges experimentally covered. Those obtained by 
$\mathrm{pH}$ titration (carried out at low concentration/ionic strength) provide the proper thermodynamic equilibrium constants. As noted before, this is not the case with the equilibrium constants obtained at high HF concentration.

To detect the main species present in solutions and to determine their formation constants, a wide variety of models has been assayed allowing to confirm that several polyhomoconjugated species are present in the tested solutions. As expected, the conjugation degree increases with the overall hydrofluoric acid concentration. The formation constants of all detected species and the relative occurrence of each one in the tested solutions have been carefully determined. It is concluded that the higher conjugated species in the most concentrated solution studied is $\mathrm{H}_{3} \mathrm{~F}_{4}{ }_{4}$, lower than the conjugation degree described for the common etching solutions (about $2.2 \mathrm{~mol} \mathrm{~L}^{-1}$, but at $91.3 \%(\mathrm{w} / \mathrm{w})$ of ethanol instead of $70 \%)$.

As far as we know, there is not already published any rigorous study about the reaction mechanisms that causes the etching of the silica surfaces by concentrated HF solutions in hydro-ethanolic media. However, the available studies and everyday practice lead to consider HF and high polyhomoconjugated species as the main species that react with the silica.

\section{Acknowledgments}

The financial support from the Spanish Government and the Fondo Europeo de Desarrollo Regional of the European Union (Project CTQ2017-88179P) is gratefully acknowledged. 


\section{References}

[1] J.L. Prom, J. Castagne, G. Sarrabayrouse, A. Muñoz-Yagüe, Influence of the preoxidation cleaning on the electrical properties of thin silica layers, IEE Proc. Part I, 135 (1988) 20-22

[2] B. Garrido, J. Samitier, J.R. Morante, L. Fonseca, F. Campadabal, Influence of the silicon wafer cleaning treatment on the $\mathrm{Si} / \mathrm{SiO}_{2}$ interfaces analyzed by infrared spectroscopy. Appl. Surf. Sci., 56-58 (1992) 861-865

[3] J. Portillo, J. Gual, G. Sarrabayrouse, J.R. Morante, Analysis of the hydrofluoric acid-ethanol cleaning process on silicon wafers with 100 vicinal surfaces, Materials Research Society Symposium, Proceedings (1993), 315 [Surface Chemical Cleaning and Passivation for Semiconductor Processing], 473-478.

[4] B. Garrido, J. Montserrat, J.R. Morante, The role of chemical species in the passivation of $<100>$ silicon surfaces by HF in water-ethanol solutions, J. Electrochem. Soc., 143 (1996) 4059-4066

[5] T. Dey, D. Naughton, Cleaning and anti-reflective [AR] hydrophobic coating of glass surface: a review from materials science perspective, J. Sol-Gel Sci. Technol. 77 (2016) 1-27

[6] N. Burham, A.A. Hamzah, B.Y. Majlis, Effect of hydrofluoric acid [HF] concentration to pores size diameter of silicon membrane, Bio-Med. Mater. Eng., 24 (2014) 2203-2209

[7] P. Kumar, P. Lemmens, M. Ghosh, F. Ludwig, M. Schilling, Effect of HF concentration on physical and electronic properties of electrochemically formed nanoporous silicon, J. Nanomaterials, (2009) Article ID 728957, 7 pages, doi 10.1155/2009/728957

[8] I.M. Campbell "Acidity and Properties of Major Industrial Acids", Chapman \& Hall, London, 1992, (Chapter 6.6)

[9] K.W. Kolasinski, The composition of fluoride solutions, J. Electrochem. Soc., 152 (2005) J99-J104

[10] A. Mitra, J.D. Rimstidt, Solubility and dissolution rate of silica in acid fluoride solutions, Geochim. Cosmochim. Acta, 73 (2009) 7045-7059 
[11] P. Luxenberg, J.I. Kim, Hydrogenfluorid- Gleichgewichte in Äthanol-WasserMischungen, Z. Phys. Chem., Neue Folge, 121 (1980) 173-186

[12] C. Ràfols, K. Herodes, J.L. Beltrán, E. Bosch, M. Rosés, lonic equilibria in aqueous organic solvent mixtures. The equilibria of $\mathrm{HF}$ in an ethanol + water mixture used for cleaning up semiconductors, J. Electroanal. Chem., 433 (1997) 77-83

[13] R.G. Bates, E.A. Guggenheim, Report on the standardization of $\mathrm{pH}$ and related terminology, Pure Appl. Chem. 1 (1960) 163-168

[14] S. Rondinini, P.R. Mussini, T. Mussini, Reference value standards and primary standards for $\mathrm{pH}$ measurements in organic solvents and water + organic solvent mixtures of moderate to high permitivities, Pure Appl. Chem. 59 (1987) 1549-1560

[15] M. Rosés, Ionic equilibria in non-aqueous solvents. Part 2. Computer programs for calculation of $\mathrm{pH}$, dissociation constants and reference potentials from potentiometric data, Anal. Chim. Acta, 276 (1993) 223-234

[16] R.M. Fuoss, T. Shedlovsky, Extrapolation of conductance data for weak electrolytes J. Am. Chem. Soc. 71 (1949) 1496-1498

[17] M. Rosés, lonic equilibria in non-aqueous solvents. Part 3. Effect of homoconjugation, Anal. Chim. Acta, 285 (1994) 391-399

[18] J. Barbosa, D. Barrón, J.L. Beltrán, V. Sanz-Nebot, PKPOT, a program for the potentiometric study of ionic equilibria in aqueous and non-aqueous media Anal. Chim. Acta, 317 (1995) 75-81

[19] A. Izquierdo and J.L. Beltrán, SOL1: a program for the simulation of complex equilibria using a personal computer, J. Chemom. 3 (1988) 209-216.

[20] M.L. Johnson and L.M. Faunt, Parameter estimation by least-squares methods, Methods Enzymol. 201 (1992) 1-37.

[21] M. Born, Volumes and heats of hydration of ions, Z. Phys. 1 (1920) 45-48

[22] B. González, N. Calvar, E. Gómez, A. Domínguez, Density, Dynamic viscosity, and derived properties of binary mixtures of methanol or ethanol with water, ethyl acetate, and methyl acetate at $T=[293.15,298.15$ and 303.15] K, J. Chem. Thermodyn. 39 (2007) 1578-1588 
[23] Y.Tanaka, T. Yamamoto, Y. Satomi, H. Kubota, T. Makita, Specific volume and viscosity of ethanol-water mixtures under high pressure, Rev. Phys. Chem. Japan, 47 (1977) 12-24

[24] G. Akerlöf, Dielectric constants of some organic solvent-water mixtures at various temperatures J. Am. Chem, Soc. 54 (1932) 4125-4139

[25] F. Hernández-Luis, M. V. Vázquez and M. A. Esteso, Activity coefficients for $\mathrm{NaF}$ in methanol-water and ethanol-water mixtures at $25^{\circ} \mathrm{C}, \mathrm{J}$. Mol. Liq., 108 (2003) 283-301

[26] H.S. Harned, B.B. Owen, "The Physical Chemistry of Electrolytic Solutions", Third Edition, Reinhold Pub. Corp. New York 1958, Chapter 7

[27] F.J.C. Rossotti, H. Rossotti, "The Determination of Stability Constants and Other equilibrium Constants in Solution", Mc.Graw-Hill, New York, 1961, p. 149 
Table 1: Physical constants of binary solvents and dissociation ( $\left.\mathrm{pK}^{0}{ }_{\text {salt }}\right)$ and limit conductivity $\left(\Lambda_{0, \text { salt }}\right)$ of potassium fluoride solutions in several ethanol-water mixtures

\begin{tabular}{|c|c|c|c|c|c|}
\hline 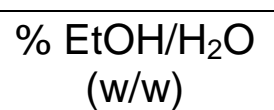 & $\begin{array}{l}\text { Density } \\
\left.\text { (g.mL }{ }^{-1}\right)\end{array}$ & $\begin{array}{l}\text { Viscosity }{ }^{\mathrm{a}} \\
\text { (mPa.s) }\end{array}$ & $\begin{array}{l}\text { Dielectric } \\
\text { constant }\end{array}$ & $\mathrm{pK}_{\text {salt }}^{0}(\mathrm{KF})$ & $\Lambda_{0, \text { salt }}(\mathrm{KF})$ \\
\hline 30 & $\begin{array}{l}0.9491^{\mathrm{a}} \\
0.9505^{\mathrm{c}}\end{array}$ & 2.074 & $\begin{array}{l}59.2^{b} \\
61.02^{c}\end{array}$ & --- & ---- \\
\hline 50 & $\begin{array}{l}0.9098^{a} \\
0.9100^{c}\end{array}$ & 2.256 & $\begin{array}{l}49.0^{b} \\
49.10^{c}\end{array}$ & $0.96 \pm 0.11$ & $45.9 \pm 0.2$ \\
\hline 70 & $\begin{array}{l}0.8646^{a} \\
0.8633^{c}\end{array}$ & 1.947 & $\begin{array}{l}38.0^{b} \\
37.95^{c}\end{array}$ & $1.22 \pm 0.10$ & $38.9 \pm 0.1$ \\
\hline 91.3 & $0.8100^{a}$ & 1.376 & $27.7^{b}$ & $1.90 \pm 0.09^{d}$ & $60.2 \pm 2.1^{d}$ \\
\hline
\end{tabular}

Table 2: Thermodynamic dissociation $\left(\mathrm{pK}^{0}{ }_{\mathrm{a}}\right.$ ) and homoconjugation ( $\log \mathrm{K}^{0}$ homo) constants of hydrofluoric acid in several ethanol-water mixtures

\begin{tabular}{|c|c|c|c|c|}
\hline \multirow{2}{*}{$\begin{array}{c}\% \\
\mathrm{EtOH} / \mathrm{H}_{2} \mathrm{O} \\
(\mathrm{w} / \mathrm{w})\end{array}$} & \multicolumn{2}{|c|}{$\mathrm{pK}^{0}{ }_{\mathrm{a}}$} & \multicolumn{2}{|c|}{$\log \mathrm{K}_{\text {homo }}^{0}$} \\
\hline & This work & Literature (11) & This work & Literature (11) \\
\hline 0 & ---- & $3.170 \pm 0.005$ & --- & $0.70 \pm 0.02$ \\
\hline 30 & $4.014 \pm 0.003$ & $3.916 \pm 0.002$ & $1.11 \pm 0.11$ & $0.94 \pm 0.01$ \\
\hline 50 & $4.497 \pm 0.003$ & $4.493 \pm 0.002$ & $1.14 \pm 0.12$ & $1.11 \pm 0.005$ \\
\hline 54.3 & --- & $4.639 \pm 0.002$ & --- & $1.08 \pm 0.015$ \\
\hline 70 & $5.403 \pm 0.003$ & $5.268 \pm 0.003$ & $1.30 \pm 0.09$ & $1.22 \pm 0.01$ \\
\hline 91.3 & $6.97 \pm 0.05^{\mathrm{a}}$ & --- & $2.21 \pm 0.03^{\mathrm{a}}$ & ---- \\
\hline
\end{tabular}


Table 3: Working parameters of fluoride electrode in several ethanol water mixtures

\begin{tabular}{ccc}
\hline$\% \mathrm{EtOH} / \mathrm{H}_{2} \mathrm{O}(\mathrm{w} / \mathrm{w})$ & $\begin{array}{c}\mathrm{pF} \text { linearity } \\
\text { range }\end{array}$ & Slope \\
\hline 0 & $<6^{\mathrm{a}}$ & $59.2^{\mathrm{a}}$ \\
30 & $2.5-4.5$ & $59.0 \pm 0.1$ \\
50 & $3.4-4.5$ & $59.1 \pm 0.2$ \\
70 & $3.4-4.5$ & $59.2 \pm 0.2$ \\
91.3 & $3.3-4.2^{\mathrm{b}}$ & $59.1^{\mathrm{b}}$ \\
\hline a: as specified from the manufacturer & \\
b: from [12] & & \\
\end{tabular}

Table 4: "Working" formation constants (as $\log \beta^{w}$ ) obtained in 50\% and $70 \%$ ethanol/water (w/w)

\begin{tabular}{ccc}
\hline & $50 \%$ ethanol/water & $70 \%$ ethanol/water \\
\hline species & $\log \beta^{\mathrm{w}}$ & $\log \beta^{\mathrm{w}}$ \\
\hline $\mathrm{HF}$ & $4.57 \pm 0.06$ & $5.60 \pm 0.01$ \\
$\mathrm{HF}_{2}^{-}$ & $5.76 \pm 0.06$ & $6.82 \pm 0.02$ \\
$\mathrm{H}_{2} \mathrm{~F}_{3}^{-}$ & $11.24 \pm 0.05$ & $10.94 \pm 0.02$ \\
$\mathrm{H}_{3} \mathrm{~F}_{4}^{-}$ & --- & $17.82 \pm 0.02$ \\
\hline
\end{tabular}

Table 5: "Working" homoconjugation constants (as log $\mathrm{K}^{\mathrm{w}}$ homo) obtained in 50\% and $70 \%$ ethanol/water (w/w) (calculated from the data of Table 4).

\begin{tabular}{ccc}
\hline & $50 \%$ ethanol/water & $70 \%$ ethanol/water \\
\hline equilibrium & $\mathrm{K}^{\mathrm{w}}$ homo & $\mathrm{K}^{\mathrm{w}}$ homo \\
\hline $\mathrm{F}^{-}+\mathrm{HF} \leftrightarrows \mathrm{HF}_{2}^{-}$ & $1.19 \pm 0.08$ & $1.22 \pm 0.02$ \\
$\mathrm{HF}_{2}^{-}+\mathrm{HF} \leftrightarrows \mathrm{H}_{2} \mathrm{~F}_{3}^{-}$ & $5.48 \pm 0.08$ & $4.12 \pm 0.03$ \\
$\mathrm{H}_{2} \mathrm{~F}_{3}^{-}+\mathrm{HF} \leftrightarrows \mathrm{H}_{3} \mathrm{~F}_{4}^{-}$ & --- & $6.88 \pm 0.03$ \\
\hline
\end{tabular}




\section{Figure captions}

Fig. 1 Potentiometric titration curves (hydrogen ion-selective electrode) obtained in $30 \%$ ethanol/water $(\mathrm{w} / \mathrm{w})$ medium, at $\mathrm{C}_{\mathrm{HF}}=$ about $5 \cdot 10^{-3} \mathrm{~mol} \mathrm{~L}^{-1}$. Symbols indicate the experimental data for titrations at initial $\mathrm{HF}$ concentration (in $\left.10^{-3} \mathrm{~mol} \mathrm{~L}^{-1}\right): \square: 4.55, \bigcirc: 4.47, \diamond: 4.47 \triangle: 4.55,+: 5.31$. Titrant solution is $\mathrm{KOH}\left(0.0992 \mathrm{~mol} \mathrm{~L}^{-1}\right.$ in $\square, \bigcirc, \diamond$ and $\triangle ; 0.0969$ in + ).

Lines correspond to the best-fitted curves.

Fig. 2 Variation of constants referred to hydrofluoric acid with the solvent composition: $\bigcirc$ dissociation constants from this work, $\square$ dissociation constants from ref. 11, $\diamond$ homoconjugation constants from this work, $\triangle$ homoconjugation constants from ref. 11. Lines correspond to the fitting models (eq. 17, solid line and eq. 18, dashed line).

Fig. 3 Potentiometric titration curves (fluoride ion-selective electrode) obtained in $70 \%$ ethanol/water $(\mathrm{w} / \mathrm{w})$ medium, up to $\mathrm{C}_{\mathrm{HF}}=5 \mathrm{~mol} \mathrm{~L}^{-1}$. Symbols indicate the experimental data for titrations at initial $\mathrm{HF}$ concentration (in $\mathrm{mol} \mathrm{L}^{-1}$ ):
$\square: 1.861$
$\mathrm{O}: 1.861$
$\diamond: 1.926$
$\triangle: 1.906+: 2.030 \quad x: 2.185$
口: 4.987
4.987
: 5.024
$\Delta: 5.024$
$\oplus: 5.024 \otimes: 5.024$

Lines indicate the calculated titration after the model.

Fig. 4 Variation of the hydrofluoric acid species concentration with the overall HF concentration in $70 \%$ ethanol/water $(\mathrm{w} / \mathrm{w})$ medium, calculated after the equilibrium constants given in Table 4. Symbols indicate the species:
$\square: \mathrm{F}^{-} \quad \mathrm{O}: \mathrm{H}$
$\diamond: \mathrm{HF}_{2}^{-}$
$\triangle: \mathrm{H}_{2} \mathrm{~F}_{3}{ }^{-}$
$\oplus: \mathrm{H}_{3} \mathrm{~F}_{4}$ 


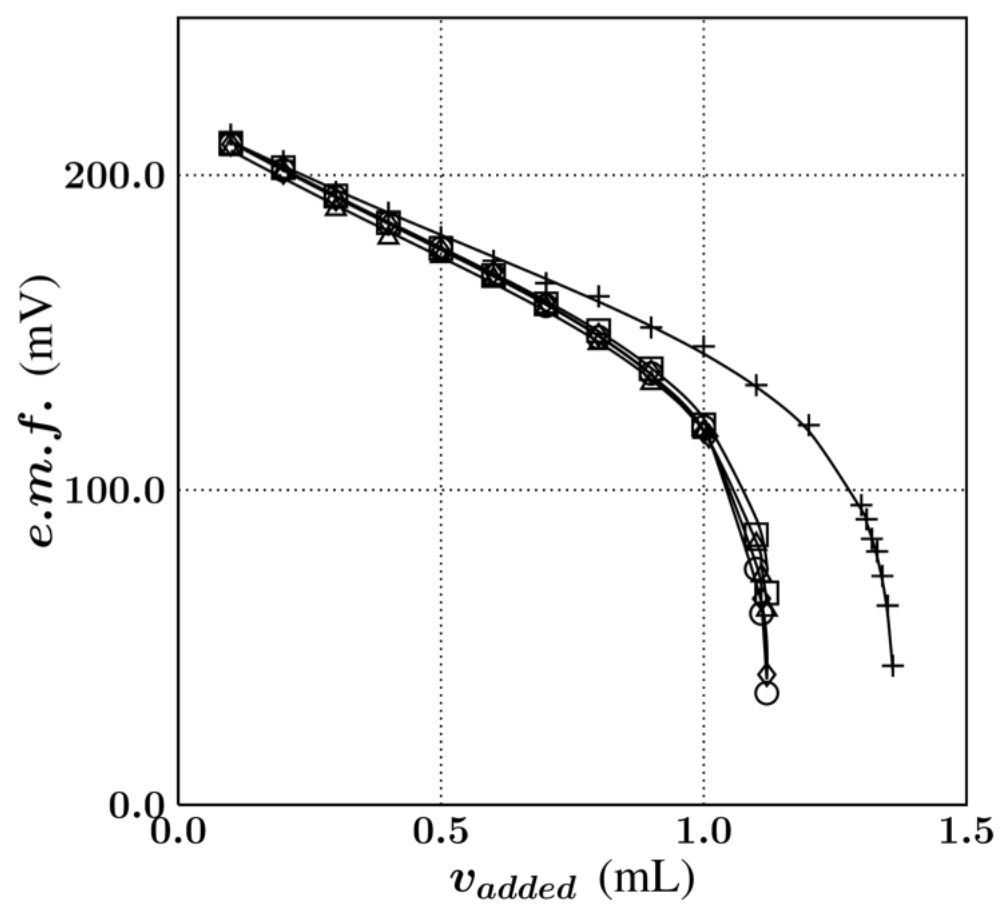

Figure 1

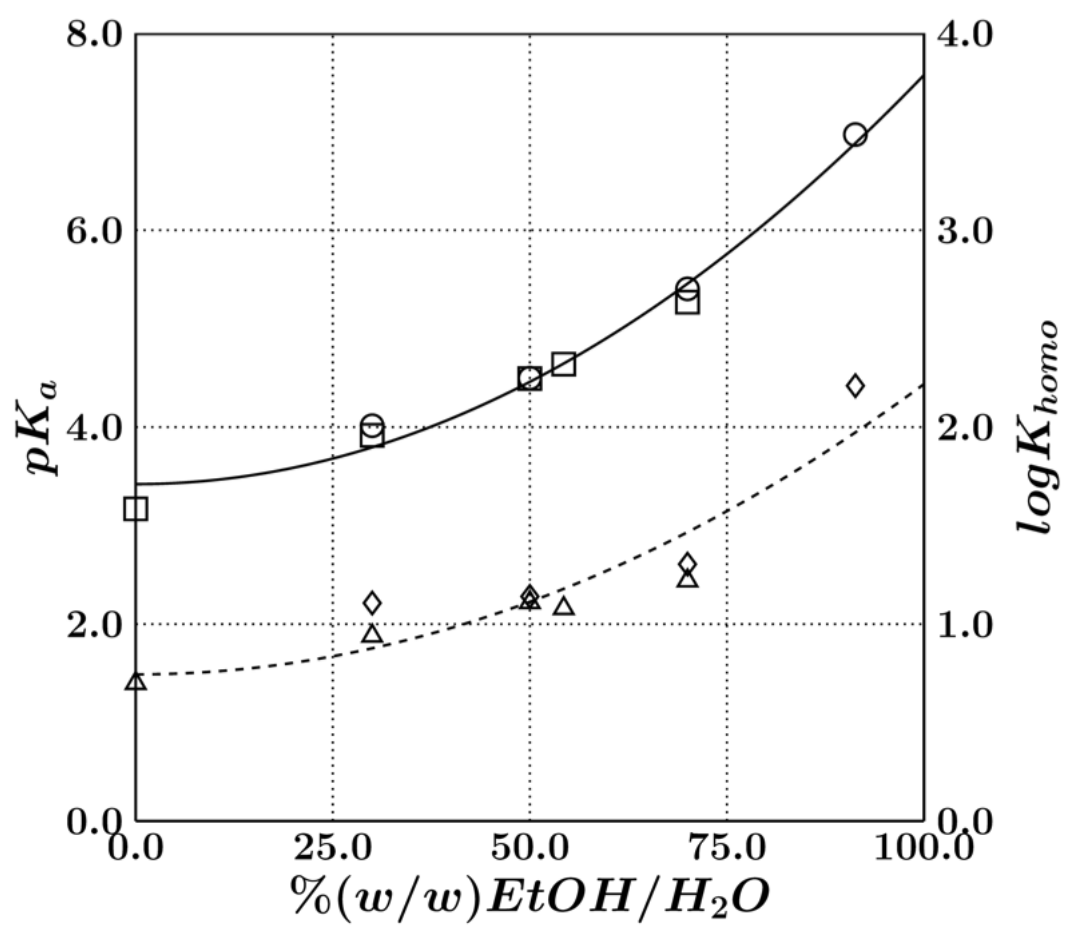

Figure 2 


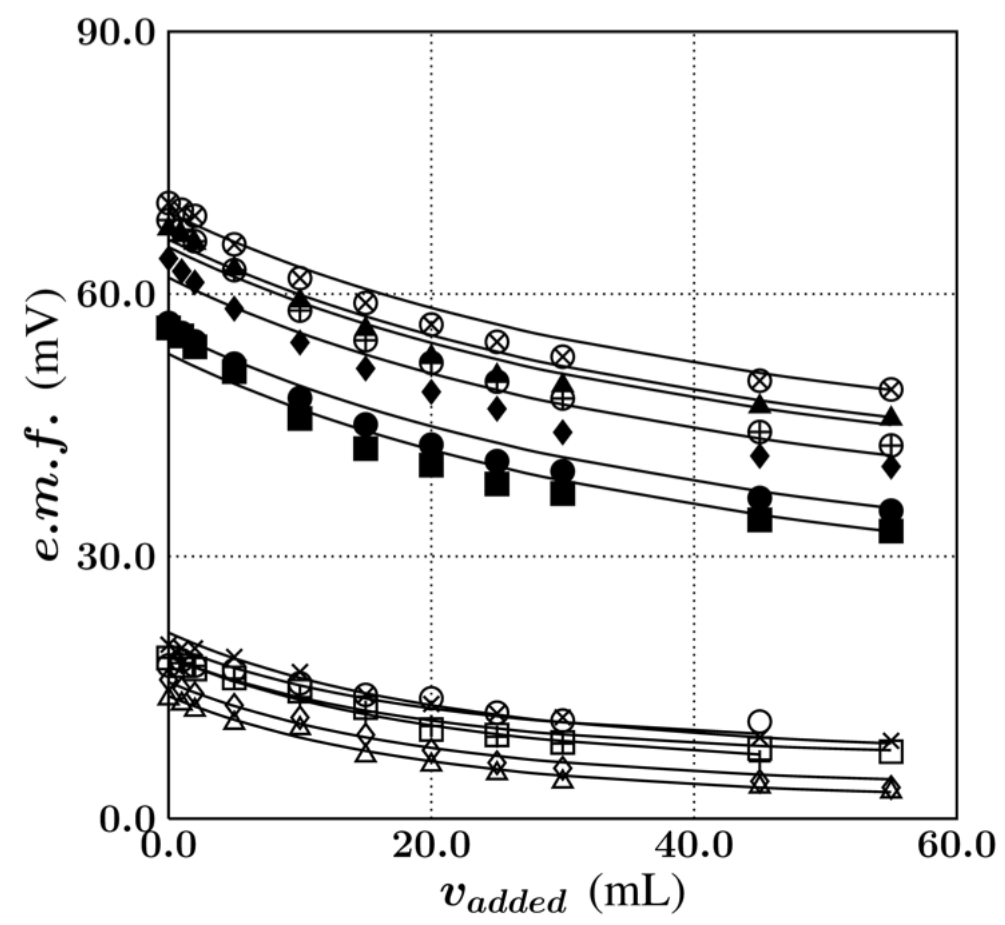

Figure 3

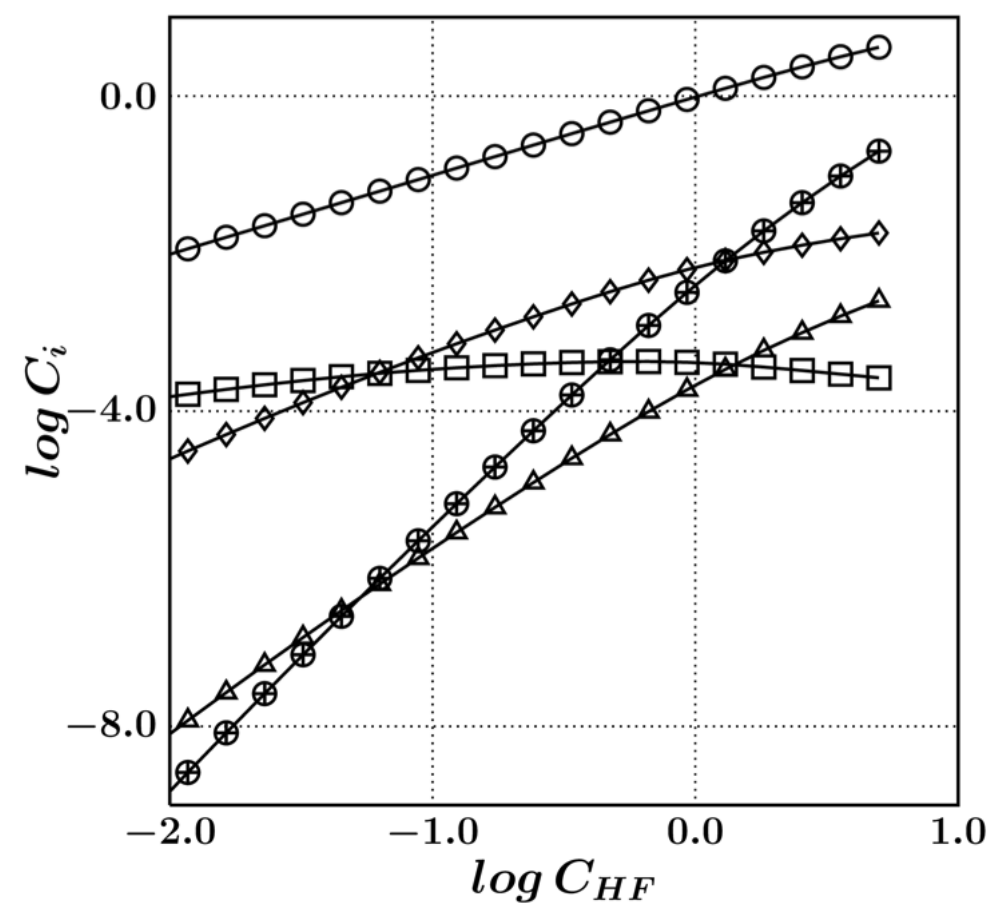

Figure 4 